\title{
Comparing the efficiency of the family among successful and unsuccessful students
}

\author{
Raouf Husseini ${ }^{1}$, Hasan Gharibi ${ }^{2}$, Mohamad Khalediann ${ }^{2, *}$ \\ ${ }^{1}$ Guidance and Counseling, Abhar Branch, Islamic Azad University, Abhar, Iran \\ ${ }^{2}$ Department of Psychology, Payame Noor University, PO BOX 19395 - 3697, Tehran, Iran \\ *E-mail address: mohamad_khaledian22@yahoo.com
}

\begin{abstract}
The current research was done to compare the efficiency of the family among successful and unsuccessful students. The statistical population of the research was high school students of Saghez. The method of the current research was causative - comparative. The research sample was 300 high school students (150 students with an average of more than 17 and students with an average of under 12) chosen through cluster sampling. Data were analyzed by using the family assessment questionnaire (FAD) and t test, multivariate regression, phi, Kendall's tau, and variance analysis. Findings, showed that there is a positive relationship with $(0 / 001)$ alpha with respect to the efficiency of the family (except for the subscale of problem - solving) among successful and unsuccessful students. The relationship of each of the demographic variables (parents' education levels, educational major, and age) was a significant relationship on the effectiveness of the family. Family is a good predictor for the success of the students and one can enhance their success rate by strengthening the family effectiveness.
\end{abstract}

Keywords: Educational success; Family effectiveness; Successful and unsuccessful students

\section{INTRODUCTION}

In today's life education forms an important part of the individual's life. By the same token, it's been close to a century, experts and psychologists have widely been considering different aspects if education, reaffirming the identification of predicting factors of the educational progress. People like Bine, Simon (1905), Thorndike (1920), Alshat and Hanker (2000) have dealt with this subject (Premuzic and Furnham, 2002). Educational progress is important from the perspective of the experts and psychologists, because what can place the person on the path o progress utilizing the people that not only have suitable mental health, but they also have gone through schools and academic levels within the educational system (Chowhury and Amin, 2006).

If there were not educational failure, other shortfalls would have been overcome. If the number of the failed children who would next become future adults of the society were low, it could have left little impact on the society. However, they are many and central parts of the cities, crowded centers are increasing a number of students whose point of character is "failure". This is an attribute, they have of themselves. The major problem of schools is the 
problem of failure. Hence, ways should be found that lead to the success of more children (Glaser, 1984). The importance of the students; educational success, has led to numerous research regarding facilitating predictors for achieving. This family is one of these predictors.

Family is more than a group of people living in a mental material environment. Family is a natural and social system that has its own special properties and is considered the primary institution of each society and is the center of the emergence of human emotions and intimate relations among people. It can be said the family performance has a considerable and direct $t$ impact on the social performance (Shakerian and Aghajani, 2008). One of the efficient aspects of the family appears in the children educational performance. Success or failure in education could result from healthy an unhealthy functions of the family through this concept(educational failure or success) is multi factorial and such factors as personal, intra organizational and extra organizational factors are involved in it (Tamannaee Far, 2007).

Generally speaking, one can state, the issue of educational progress and success are largely entrenched in the quantity and particularly quality of the current students' relations with their families and parents. Research findings suggest more, direct and warmer facilitated relationship of the students with their families and parents leave significant impacts on the improvement of the students' educational situation (Mazaheri, 2008). Family at the age of 210 teaches skills to the child that play fundamental roles in educational and schools issues. These skills are language, learning ability, aspects of the need to progress and considering duties.

Although families differ in teaching these skills to children, the result of the actions by the families in creating these skills is extraordinary (Bloom, 1982). English researchers including, Foley, Roc he and Tucker (2001) point out families formed by external factors and cultural forces create wisely and exactly the lives of their children. In a major educational finding in the United States. Braunger and Lewis (1998) concluded education (literacy) is in the heart of the familial life and depends indirectly on the interpersonal interaction (reciprocal effects) with children through providing educational conditions at home and providing a positive motivational an emotional environment. Given the findings by Hill and Yeung (2000) the social- mental sources provided by parents including continuous parental supervision and clemency will result in a situation where students feel secure and their adaptability will become easier.

They have emphasized on the parents' education hopes, and their expectations of their children. Their research includes an investigation of the relationship between parents' expectations and students' educational performance during time periods. Results refer to the fact that parental low expectations will lead to lower motivation and weaker performance on the part of the students. For Mazaheri (2008), the quality of parents'; relationship with children and parents' control levels are thought to be the main components in increasing the mental well-being and success of the students . Better relations between parents and children, sympathy about problems, exchange of views about social and educational issues will caus4e a sense of self sufficiency an d motivation for attaining later successes in education. Based on the issues mentioned, we'll investigate in this research if family efficiency differs among the successful and unsuccessful students? According to the research literature, the main hypotheses of this research are that the family effectiveness is different among the successful and unsuccessful students. The family efficiency of the students is related to demographic variables (age, parents' education, and education degrees). 


\section{RESEARCH METHOD}

The current research was done to compare the efficiency of the family among successful and unsuccessful students. The statistical population of the research was high school students of Saghez. The method of the current research was causative - comparative. The statistical population of this research includes all the boy students of Saghez high schools in the educational year of 2011-2012 who were 1800 people. They were examined based on the Cochran formula and Morgan's table.

The number of examinees participating as the main sample was 300 male students, including 150 whose previous year's average was over 17 and still 150 others whose previous year's average was under 12. They were selected through cluster sampling. To collect data, first the list of all the high schools of the city was prepared by the education department and from among these schools, 5 schools were chosen randomly. While visiting in person to these schools, helped by bureaucratic affairs personnel and investigating the educational papers of the learners, successful students (average of 17) and unsuccessful students (average under 12) were segregated and the students in question chosen randomly from among the classes of these schools were specified.

In this research, in accordance with obtaining permit from the education department of Saghez, the researcher refer to boys high schools, described briefly the objectives of the research for the respondents, demanding them to spend some time with the researcher. The intimate relationship with the respondent, having been established, first the McMaster family efficiency questionnaire, then self-concept questionnaire were completed and in case, the respondent had a question regarding the questions and items, they received answers warmly and in the end completed questionnaires were collected.

\section{1. Research tools}

In order to measure the family efficiency, the family measurement scale and to investigate self-concept, the Beck self-concept scale were used. The FAD scale was formulated based on the McMaster model with the aim of describing family structures and organizational characteristics (Epstin, Bysharop and Beldwin, 1983). The mentioned tool to differentiate healthy and patient families, used to evaluate exchange patterns among family members.

This tool involves 60 questions. To score, using a four degree spectrum consisted of 1 (totally agree) to 4 (totally disagree) each question was scored 1 to 4 . Phrases describing an unhealthy performance receive inverse scores. High scores indicate poor performance and lower scores indicate healthier performance (Najarian, 1995; quoted by Shakerian and Aghajani, 2008). This pattern determines structural and professional and interactive properties of the family and specifies six aspects of the family performance (problem -solving, roles, emotional reaction, communication, behavior control, and emotional attachment).

Hence, the test measuring family quite in proportionate to these six aspects consists of six subscales for measuring them, plus another subscale related to the overall family performance (Sanaee, 2000). This test being administered by Epstin, Beldwin and Bysharp (1982), was conducted over a sample of 503. The alpha coefficient range of its subcategories was $0 / 72-0 / 92$, suggesting a relatively good internal consistency. Research conducted in Iran, reaffirms the validity and reliability of this test. For example Najarian, 1995; Molanaghi, 1998; Zademohamad, 2008; Shakerian and Aghajani, 2008 showed that the Cronbach alpha coefficient as $0 / 92$. 


\section{FINDINGS}

Table 1. T test for comparing successful and unsuccessful students in subscales and the sum of the family efficiency.

\begin{tabular}{|c|c|c|c|c|c|c|}
\hline \multirow{2}{*}{$\begin{array}{c}\text { Success or failure of } \\
\text { then family efficiency }\end{array}$} & \multicolumn{2}{|c|}{ Successful students } & \multicolumn{2}{c|}{ Failed students } & \multirow{2}{*}{ T value } & Sig \\
\cline { 2 - 6 } & $\begin{array}{c}\text { Standard } \\
\text { deviation }\end{array}$ & Average & $\begin{array}{c}\text { Standard } \\
\text { deviation }\end{array}$ & $\begin{array}{c}\text { Standard } \\
\text { deviation }\end{array}$ & \\
\hline General function & $5 / 049$ & $25 / 333$ & $5 / 925$ & $27 / 191$ & $-2 / 388$ & $0 / 018$ \\
\hline Behavior control & $3 / 019$ & $18 / 990$ & $3 / 501$ & $21 / 409$ & $-5 / 232$ & $0 / 0001$ \\
\hline Emotional attachment & $2 / 803$ & $15 / 252$ & $3 / 290$ & $16 / 695$ & $-3 / 338$ & $0 / 0001$ \\
\hline Emotional reaction & $2 / 888$ & $12 / 812$ & $2 / 996$ & $14 / 328$ & $-3 / 642$ & $0 / 0001$ \\
\hline Roles & $4 / 166$ & $25 / 693$ & $3 / 529$ & $27 / 336$ & $-3 / 009$ & $0 / 003$ \\
\hline Communications & $3 / 165$ & $19 / 957$ & $3 / 362$ & $22 / 222$ & $-4 / 904$ & $0 / 0001$ \\
\hline Problem solving & $2 / 388$ & $2 / 504$ & $12 / 338$ & $0 / 591$ & $12 / 152$ & $0 / 538$ \\
\hline $\begin{array}{c}\text { Sum of then family } \\
\text { efficiency }\end{array}$ & $130 / 37$ & $141 / 33$ & $17 / 517$ & $-4 / 247$ & $18 / 941$ & $0 / 0001$ \\
\hline
\end{tabular}

To sum up , the family efficiency consisted of all the subscales were measured by using the $t$ test. Given the test score of $t-4 / 427$ and the significance level of $0 / 0001$, it is concluded that the family efficiency among the successful and unsuccessful students has a significant difference with the alpha level of $(0 / 01)$.

Table 2. The Kendall's tau for comparing the relationship of the variable of father's education with the family efficiency.

\begin{tabular}{|c|c|c|c|c|c|c|c|c|}
\hline \multirow{2}{*}{\multicolumn{2}{|c|}{ Variable }} & \multicolumn{6}{|c|}{ Family efficiency } & \\
\hline & & So much & Much & Medium & Little & So little & Sum & \\
\hline \multirow{6}{*}{ 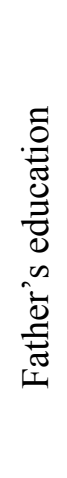 } & Illiterate & 0 & 10 & 16 & $1 / 5$ & 0 & $27 / 5$ & \multirow{6}{*}{$\begin{array}{c}\text { Sig }=0 / 009 \\
\text { Kendall's } \\
\text { tau_b }=0 / 161\end{array}$} \\
\hline & Elementary & 0 & $11 / 5$ & 16 & 2 & 0 & $29 / 5$ & \\
\hline & $\begin{array}{l}\text { Junior high } \\
\text { school }\end{array}$ & 0 & $4 / 5$ & 11 & $0 / 5$ & 0 & 16 & \\
\hline & High school & $1 / 5$ & 6 & 6 & 0 & 0 & $13 / 5$ & \\
\hline & $\begin{array}{c}\text { University } \\
\text { level }\end{array}$ & $0 / 5$ & $8 / 5$ & 4 & $0 / 5$ & 0 & $13 / 5$ & \\
\hline & Total & 2 & $40 / 5$ & 53 & $4 / 5$ & 0 & 100 & \\
\hline
\end{tabular}


Data indicated that families with fathers having educating levels more than junior, elementary, and Illiterate levels have had higher efficiency while families with fathers having academic education levels or even higher have had more and more efficiency. Using the Kendall's tau_b, this relationship has a significant relationship with the alpha of 0/01.

Table 3. The Kendall's tau test for comparing the relationship of the variable of mother's education with the family efficiency.

\begin{tabular}{|c|c|c|c|c|c|c|c|c|}
\hline \multirow{2}{*}{\multicolumn{2}{|c|}{ Variable }} & \multicolumn{6}{|c|}{ Family efficiency } & \\
\hline & & $\begin{array}{l}\text { So } \\
\text { much }\end{array}$ & Much & Medium & Little & $\begin{array}{c}\text { So } \\
\text { little }\end{array}$ & Sum & \\
\hline \multirow{6}{*}{ 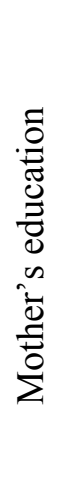 } & Illiterate & 0 & $15 / 5$ & 26 & 2 & 0 & $43 / 5$ & \multirow{6}{*}{$\begin{array}{c}\text { Sig }=0 / 001 \\
\text { Kendall's } \\
\text { tau_b }=0 / 152\end{array}$} \\
\hline & Elementary & 0 & $12 / 5$ & 18 & 1 & 0 & $31 / 5$ & \\
\hline & $\begin{array}{c}\text { Junior high } \\
\text { school }\end{array}$ & 1 & 5 & 4 & 1 & 0 & 11 & \\
\hline & High school & 1 & $4 / 5$ & $0 / 52$ & $0 / 5$ & 0 & 8 & \\
\hline & $\begin{array}{c}\text { University } \\
\text { level }\end{array}$ & 0 & 3 & 3 & 0 & 0 & 6 & \\
\hline & Total & 2 & $40 / 5$ & 53 & $4 / 5$ & 0 & & \\
\hline
\end{tabular}

Data showed that families with mothers' having the educational levels of high and junior schools and academic levels have been more effective than families with mothers having elementary or illiterate levels. Using the Kendall's tau_b, one can say that there is a direct an positive relationship between the mother's education level and the family efficiency.

Table 4. Phi test for comparing the relationship of the family efficiency with the educational major.

\begin{tabular}{|c|c|c|c|c|c|c|c|}
\hline \multirow{2}{*}{ Variable } & \multicolumn{6}{|c|}{ Family efficiency } & \\
\cline { 2 - 8 } & $\begin{array}{c}\text { So } \\
\text { much }\end{array}$ & Much & Medium & Little & $\begin{array}{c}\text { So } \\
\text { little }\end{array}$ & Sum & \\
\hline $\begin{array}{c}\text { Technical-Kardanesh } \\
\text { (art school) }\end{array}$ & $0 / 5$ & 8 & 22 & 2 & 0 & $32 / 5$ & $\begin{array}{c}\text { Sig }= \\
0 / 001 \\
\text { Theoretical }\end{array}$ \\
\hline Sum & $1 / 5$ & $32 / 5$ & 31 & $2 / 5$ & 0 & $67 / 5$ & $\begin{array}{c}\mathrm{Ph} \mathrm{i}= \\
0 / 23\end{array}$ \\
\hline
\end{tabular}

According to the frequency distribution of the samples, using the Phi test, this relationship was measured. With the alpha of $(0 / 01)$ the families of the students majoring in the theoretical courses have the highest efficiency with respect ct to the families of the students majoring in technical Kardanesh courses. 
Table 5. Kendall's tau test for comparing the relationship of the age of ten student and the family efficiency.

\begin{tabular}{|c|c|c|c|c|c|c|c|c|}
\hline \multirow{2}{*}{\multicolumn{2}{|c|}{ Variable }} & \multicolumn{6}{|c|}{ Family efficiency } & \\
\hline & & So much & Much & Medium & Little & $\begin{array}{c}\text { So } \\
\text { little }\end{array}$ & Sum & \\
\hline \multirow{6}{*}{ 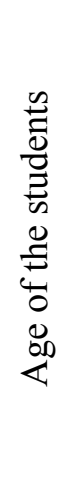 } & Age 15 & $0 / 5$ & 5 & 2 & 0 & 0 & $7 / 5$ & \multirow{6}{*}{$\operatorname{Sig}=0 / 010$} \\
\hline & Age 16 & 1 & 10 & 15 & $0 / 5$ & 0 & $26 / 5$ & \\
\hline & Age 17 & 0 & $15 / 5$ & 17 & 2 & 0 & $34 / 5$ & \\
\hline & Age 18 & $0 / 5$ & $8 / 5$ & $13 / 5$ & $1 / 5$ & 0 & 24 & \\
\hline & Age 19 & 0 & $1 / 5$ & 3 & $0 / 5$ & 0 & 5 & \\
\hline & Age 20 & 0 & 0 & $2 / 5$ & 0 & 0 & $2 / 5$ & \\
\hline \multicolumn{2}{|r|}{ Sum } & 100 & 0 & $4 / 5$ & 53 & 40 & 2 & \\
\hline
\end{tabular}

According to the frequency distribution of the samples, using the Phi test, this relationship was measured. With the alpha of $(0 / 01)$ the families if the students whose age was higher had lower efficiency for as much as 0/15 compared to the students whose age higher.

\section{DISCUSSION AND CONCLUSIONS}

Findings indicated that the family efficiency is different among the successful and unsuccessful students. In other words. Successful students enjoy a more favorable situation in terms of the family efficiency. In each of the subscales of the family efficiency measurement (except for the subscale of problem solving), there is a significant difference between the two groups of the students, i.e. as the subscales increase, the students' success will increase.

To explain these data, on can say that education (literacy) is in the heart of the familial life and depends indirectly on the interpersonal interaction (reciprocal effects) with children through providing educational conditions at home and providing a positive motivational an emotional environment. Given the findings by Hill and Yeung (2000) the social- mental sources provided by parents including continuous parental supervision and clemency will result in a situation where students feel secure and their adaptability will become easier.

The results of theirn resercah are in line with those of the reseracvh by Braunger and Lewis (1998), Bandura (2011), Eddy, Bruyn and Dekovi and Meijnen (2003), Bandura (2006), Barker and Maloney (2000), Monks and Heller and Passow (2000), Forges and Abochar (2006), Hill and Yeung (2000). Findings of the research by Shakerian and Aghajani (2008) suggest that there is a significant relationship between ted family efficiency of the family and educational levels of the two groups of the students.

In a research, concerning the parents (migrants) in the United States, but Goldenberg et al, 2001, on factors like parents' educational hopes and through expectations of their children have been emphasized. The findings indicated that lower parental expectations will lead to lower expectations and poor performance by the students. 
Research show when students are exposed to a supporting environment at home emotionally when the educational success is affirmed and their educational scores will improve considerably (Clark, 2000). One of the findings of the research was that with respect to other problem solving scale, contrary to other scales, there has been no significant difference with regards to the scores of the two groups of the students.

To explain these findings, one can say that on of the possible reasons could be the type of the questions these subscales include. Maybe, the concept of the power to solve these problems has not been measured well. Also, other factors excepting the family structure could affect the family efficiency like (the way problem solving methods are taught, making decisions at critical occasions through parents to children $m$ the poor ability of the parents in seeking suitable ways to solve the problems existing in the family and factors including cultures and educational facilities) (Alizade, Sahraee, 2009).

\section{1. The second hypothesis}

There is a relationship between demographic variables and family functions. The results of the relationship of each of the demographic variables (age, students' educational major, father and mother's education) on the sum of the family functions.

There is a direct and positive relationship between parents' education and the family efficiency. To explain these data $\mathrm{m}$ it should be noted that higher levels of the family education will help students' educational success through different ways.

For example, in an investigation of the successful students (qualified), students whose mothers have lower skills levels, are more likely have little experiences than other students, they are more likely to use general libraries, belonging to other groups outside the school and participate to a lesser extent in the activities related to music. These factors are totally related to the higher scores in the success scales (Barker and Maloney, 2000).

Also, the findings of this research showed that these results are in line with those of Wylie. According to Wylie's findings (2001), students whose mothers had deserted school without attaining skills are the ones that have lower scores than others and contrary those whose mothers have academic degrees, have higher scores. The results of this research are in concert with those of the research by Willington (2001), Adam et al. (2000).

There is a positive relationship between the family efficiency and the students. To explain this rationally, on can say that the positive relationship between the family efficiency and age means that as the age of the students increases the family efficiency will decline due to t effects of the peers, educational environment, teachers' styles, and the motivation of the students (Peterson, 2002, quoted Tamanaee Far, 2007).

The families of the students majoring in theoretical courses are more efficient than families with students majoring technical and Kardanesh courses. To explain these data, it should be noted that due to lack of industrialization, the statistical population of the researcher will enroll families with students majoring inn theoretical courses.

The parental child relationship is one of the most effective relations that people can experience and one cam say that one of the main grounds of the etiology, prediction, and pre awareness of the change trend in investigating the educational and social position of the children can be sought in the way parents-children are formed (Mazaheri, 2008). In the first years of childhood, the type of the relation and $\mathrm{p}$ [are in the United States. Braunger and Lewis (1998) concluded education (literacy) is in the heart of the familial life and depends indirectly on the interpersonal interaction (reciprocal effects) with children through providing educational conditions at home and providing a positive motivational an emotional environment. Given the findings by Hill and Yeung (2000) the social mental sources provided by parents including 
continuous parental supervision and clemency will result in a situation where students feel secure and their adaptability will become easier, behavior are considered to be the main factors in the development of the child's personality.

The child will imitate the first behavioral patterns in the family environment from his own parents. Based on the conducted investigations, it looks that the family leaves the highest impact on the educational progress and achievements of the students as well as on their positive self- concept of the students. From the perspective of the family trends, in the form of stable house environment, providing a series of experiences, activities, interaction and all out support by the parents, and their learning are the most important factors in their success.

Also, a healthy environment at home, by the parents, mentally, materially and emotionally affect their success rates. Education (literacy) is in the heart of the familial life and depends indirectly on the interpersonal interaction (reciprocal effects) with children through providing educational conditions at home and providing a positive motivational an emotional environment.

In the current research, due to gender segregation an the research conditions in the educational system, high schools boys were chosen. This limitation can affect the results of the generalization of the research, hence, it is recommended that in later papers, two sexes of girls and boys are selected and compared from other courses too. In the end we thank all those who helped us fulfill our research an we are grateful to those that participated in our research.

\section{References}

[1] Bloom Benjamin, (1995), Human characteristics and institute learning, (trans. By Aliakbar, Seif), Tehran: University publication

[2] Tamanaeefar, Mohamadreza (2007), Investigating the comparison of the factors affecting the educational fallout of the students who have failed and passed their courses, Scientific and research periodical of Daneshvar rafter, 39-52

[3] Sanaee Bagher (2000). Scales of evaluating family and marriage, Tehran: Besat Publication.

[4] Delavar Ali (2006). Research methods in psychology and educational science, Tehran: PNU publications.

[5] Delavar Ali (2008). Probabilities ad applied statistics in psychology and educational science, Tehran: Roshd publication.

[6] Zademohamadi Ali, Family research quarterly 7 (2006) 256.

[7] Shakerian Ata, Aghajani and Tahmoreth (2009), Investigation and comparison of the family efficiency in relation with the students' educational levels, both successful and unsuccessful at the Azad university of Sanandaj, Social research paper, 187-201.

[8] Alizade Sahraee, M. Hani (2009). The relationship of the family efficiency with the positive and negative perfectionism among the students of the city of Noshahr, M.A. thesis

[9] Christian A., Ryan Natanbee, Epstin Gabourai; Keets Ivan W., Miller Duan, S. Bysharp (2011), Family therapy (McMaster approach) (Trans. Mohsen Dehghani and Maryam Abbasi), Tehran: Roshd publication 
[10] Glaser William (2001). Schools without failure, trans by, Hanze Sade, Tehran: Roshd Publication.

[11] Goldenberg Irne, Goldenberg Herbert (2010). Family therapy, (Trans. By, Hussein Shahi, Bravati, Dr. Syamak Naghshbandi) and Vale Arjomand(co translator), Tehran: Ravan publication.

[12] Mahmoodian Hussein, Journal of social sciences and Humanities 4 (2006) 153-184.

[13] Mazaheri Ali (2008). Investigating the impact of the parents' supervisioncommunication behavior on the social and educational level of the students, Family research house, final report of the research plan of the ministry of technology and research.

[14] Molanaghi F. (1998), The performance situation of the families and the women mental health among the polygamy families, M.A thesis, Islamic Azad University.

[15] Najarian Farzane (1995), Factors affecting the family: investigating the psychometric characteristics of the family scale, Roudehen Azad university, M.A. thesis

[16] Adedipe T. S., Science Education 66 (1994) 547-563.

[17] Alfeld-Liro C., Sigelman C. K., Journal of Youth and Adolescence 27(2) (1997) 219-244.

[18] Al-Zyoudi Mohammed, International Journal of Special Education 22(1) (2007) 132-136.

[19] Bakare C. K., Journal of Educational Computing Research 38(2) (1987) 139-153.

[20] Bandura A., Applied psychology an international review 60(3) (2011) 421-448.

[21] Barker G., Maloney T. (2000). Final regression Resuts on the cognitive Achievement of Children in thE Christchurch Health and Development study with corrections for attrition from this longitudinal study. Treasury Wotking Paper 00/6.

[22] Beck A. T., Steer R. A., Epstin N., Brown B., Psychological assessment 2(2) (1990) 191-197.

[23] Bong M., Skaalvik E. M., Educational psychology Review 15(1) (2003) 1-40.

[24] Braunger J., Lewis J. P. (1998). Building a Knowledge Base in Reading. (3rd ed.) Northwest Regional Educational Laboratory \& NCTE \& International Reading Association.

[25] Chowhury M. S., Amin M. N., Social Behavior and personality 28 (2006) 433-449.

[26] Clark F. S., Dissertation Abstract International 49 (2000) 17-58.

[27] Damon W., Hart D. (1991). Self-understanding in childhood and adolescence. Canada: Cambridge University Press.

[28] Dekrefflin R., Canadian Journal of Education 18 (2003) 234-241.

[29] Dinah M. M. (2004). The relationship between a Disadvantaged Home. Environment and The self-concept of children: A Guidance and conselling perspective. PH. D Thesis in Psychology of Education university of South Africa.

[30] Eddy H., Bruyn D., Dekovi M., Meijnen G. W., Journal of Applied Development psychology 24 (2003) 393-412. 
[31] Foluke-Henderson Nzinga E., Dissertation Abstracts International 67(12) (2007) 449-A.

[32] Goldenberg C., Gallimore R., Reese L., Garnier H., Academic Educational Research Journal 38(3) (2001) 547-572.

[33] Harter S. (1998). The Development of Self- Representations. In N. Eisenberg (Ed.), Social, Emotional and Personality Development (5th ed Vol. 3, pp. 553-617). New York: Wiley Holbrook (Eds): Foundations of Education, 1: 135-156.

[34] Hill M. S., Yeung W. J. (2000). Behavior and Status of Children, Adolescents and Young Adults. Paperprepared for the conference on generations and gender, United Nations Economic Commission for Europe Population Activities Unit, Geneva, Switzerland. Institute for Social Research, University of Michigan.

[35] Monks F. J., Heller K. A., Passow A. H. (2000). The Study of Giftedness: Reflections on where we are and where we are going). In K.A. Heller, F.J. Monks, R.J. Sternberg, R.F. Subotnik, (Eds.) International Handbook of Giftedness and Talent.). Oxford: Elsevier Science Limited.

[36] Pajares F., Urdan T. (2006). Self-efftcacy beliefs of adolescents. Greenwich, CT: IAP.

[37] Park Jungwee (2003). Adolescent Self-concept and Health into Adulthood. Statistics Canada, Annual Report.

[38] Premuzic T., Furnham A., European Journal of Personality 17 (2003) 237-250.

[39] Tracy Jason F., Dissertation Abstracts International 67(8) (2007) 2842-A.

[40] Tuttel D., Tuttel N. (2004). Self-esteem and Adjusting with Blindness. 3rd Edition, Springfield, IL. Charles C Thomas.

[41] Wilson W., Constantine M. G., Journal of Black Students 29(3) (1999) 354-366.

[42] Fateme Taghva, Narges Rezaei, Javad Ghaderi, Roghaye Taghva, International Letters of Social and Humanistic Sciences 14 (2014) 18-25.

[43] Gholamreza Jandaghi, Hamid Reza Irani, Ehssan Jandaghi, Zeinab Sadat Mousavi, Maryam Davoodavabi, International Letters of Social and Humanistic Sciences 15(1) (2014) 7-13.

[44] Heman Mahmoudfakhe, Morad Abdivarmazan, Toba Amini, International Letters of Social and Humanistic Sciences 15(2) (2014) 84-91. 